\title{
Correlates of Anogenital Injuries in Adolescent Females
}

\author{
Peter V. Bui ${ }^{1}$, Carolyn J. Sachs ${ }^{2 *}$, Malinda Wheeler ${ }^{3}$ \\ ${ }^{1}$ David Geffen School of Medicine at UCLA, Los Angeles, USA; ${ }^{2}$ Department of Emergency Medicine, David Geffen School of \\ Medicine at UCLA, Los Angeles, USA; ${ }^{3}$ Forensic Nurse Specialists, Inc., Los Alamitos, USA. \\ Email: csachs@ucla.edu
}

Received October $10^{\text {th }}, 2013$; revised November $8^{\text {th }}, 2013$; accepted December $6^{\text {th }}, 2013$

Copyright (C) 2014 Peter V. Bui et al. This is an open access article distributed under the Creative Commons Attribution License, which permits unrestricted use, distribution, and reproduction in any medium, provided the original work is properly cited. In accordance of the Creative Commons Attribution License all Copyrights (C) 2014 are reserved for SCIRP and the owner of the intellectual property Peter V. Bui et al. All Copyright (C) 2014 are guarded by law and by SCIRP as a guardian.

\section{ABSTRACT}

Objective: We sought to investigate correlates of anogenital injuries (AGIs) in adolescents. Methods: Our retrospective study included sexually assaulted female patients aged 12 to 17 reporting attempted or completed vaginal or anal penetration between 2002 and 2011. Forensic nurses performed anogenital examinations using colposcopy, digital macrovisualization, and toluidine blue dye application. We reviewed case files for AGIs and demographic and sexual assault characteristics. Results: Of the 1961 sexual assault examinations that met our inclusion criteria, 59.6\% displayed AGIs. Our logistic regression model using 1752 examinations found the following variables associated with less injury: intercourse within 5 days prior to assault $(\mathrm{OR} 0.72,95 \% \mathrm{CI}=0.55$ to 0.95); post-coital interval of 49 - 72 (OR $0.50,95 \% \mathrm{CI}=0.36$ to 0.71 ), 73 - 96 (OR $0.41,95 \% \mathrm{CI}=0.25$ to 0.68 ), and $97-120$ hours (OR $0.26,95 \% \mathrm{CI}=0.13$ to 0.51 ). Only lack of prior sexual experience was associated with increased injury (OR 2.01, 95\% CI $=1.58$ to 2.55$)$. Conclusions: In our adolescent patient population, examination findings of AGIs correlate with variables related to time from assault and prior sexual experience.

\section{KEYWORDS}

\section{Sexual Assault; Statutory Rape; Female Adolescents; Anogenital Injury; Forensic Nursing}

\section{Introduction}

Medical professionals are often the first contact for sexually assaulted minors, and relevant findings, particularly physical injuries, including anogenital injuries (AGIs), may be available for a brief period of time [1,2]. In addition to administering appropriate medical care, focusing on specific factors that provide the greatest medicolegal yield should be a priority. In this study, we expanded on our prior study of AGIs in adult women by examining correlates in an adolescent population [3]. We hypothesized that intercourse 5 days prior, stranger assault, and sexual inexperience would be associated with increased injury while alcohol use, consent, drug use, lapse of consciousness, child birth, increasing post-coital interval, and weapon involvement would be associated with less injury.

${ }^{*}$ Corresponding author.

\section{Materials and Methods}

\subsection{Study Design}

Forensic nurses, also known as sexual assault nurse examiners (SANEs), performed sexual assault examinations using colposcopy or a high quality digital camera and toluidine blue dye application to examine for injury, per the protocol recommended by the State of California (CA). SANEs entered case data into a proprietary database program, TACT (Thorough Assault Case Tracking, Infosys Business Solutions, Cypress, CA, USA), developed to accommodate the SANE casework. Our study was approved by the Institutional Review Board.

We defined the dependent variable AGI as any abrasion, laceration, or ecchymosis to the genitalia or anus and rectum. We reviewed case files and the TACT database for a number of independent variables, which were binary (no, yes) unless otherwise indicated: patient age $(12,13,14,15,16,17)$; patient alcohol use; condom use; 
consent; number of deliveries $(0,1+)$; cognitive disabilities; physical disabilities; patient drug use; patient education (college, elementary school, high school, junior high school); gravidity $(0,1+)$; intercourse 5 days prior to the assault; lapse of consciousness; lubricant use; patient marital status (cohabitating, married, separated, single); parity $(0,1+)$; penetration of the vagina and anus by penis, finger, or object; perpetrator relationship; post-coital interval (0 - 24, 25 - 48, 49 - 72, 73 - 96, 97 - 120 hours); patient race (Asian, African American/Black, Filipino, Hispanic, White, Native American, other); patient position during assault (back, multiple, sitting, standing, stomach, hands/ knees, other); patient reporting prior sexual intercourse; and weapon involvement. We collapsed a number of independent variables to be binary: marital status (single, not single), perpetrator relationship (stranger, not stranger), and race (black, non-black).

The independent variables included "unknown" as a response, if applicable, indicating that the patient could not or did not provide an answer when asked a question pertaining to the independent variable. Successful penetration and attempted penetration were grouped together into a single response as defined in the California penal code to accommodate an inability of patients to distinguish for certain between successful penetration and attempted penetration during an assault.

\subsection{Selection of Participants}

Our study population consisted of female patients between 12 and 17 years inclusive who reported attempted or completed vaginal or anal penetration and consented to a forensic anogenital examination within 120 hours of a sexual assault between November 1, 2002, and May 31, 2011, in our geographic area. Individuals involved in multiple forensic examinations during the study period had a case file for each incident.

\subsection{Data Analysis}

We used Pearson's chi-square test and Fisher's exact test to analyze the association between AGIs and the selected independent variable. We calculated odds ratios (ORs) with a logistic regression using the dependent variable AGI and a single independent variable (ignoring unknown responses except for those of penetration).

We further explored correlates of AGIs with a logistic regression model choosing independent variables based on prior work and plausible association with injury $[3,4]$.

For binary independent variables, the reference category was "no" or a clinically or epidemiologically relevant category. For the categorical independent variables, the reference category was the category associated with 0 , the lowest number, or a clinically or epidemiologically relevant category.

We used Microsoft Excel 2010 (Microsoft Corp., Redmond, WA, USA) for data management and Stata 12 (StataCorp LP, College Station, TX, USA) for analysis.

\section{Results}

Our group performed 1961 examinations on female patients aged 12 to 17 years inclusive within 120 hours of a sexual assault between November 1, 2002, and May 31, 2011 (Figure 1). Of these 1961 examinations, 1926 examinations involved distinct individuals, 28 examinations involved one individual for two examinations each, three examinations involved one individual, and four examinations may have involved two individuals in two examinations each but could not be verified. Complete data, meaning that there were not any unknowns across all independent variables except for anogenital penetration, were available for 1233 (62.9\%) examinations. We found AGIs in 1169 (59.6\%) of examinations.

Variables found to correlate with AGIs in bivariate analysis (Table 1) included alcohol ( $p=0.047)$, intercourse 5 days prior $(p<0.001)$, post-coital interval $(p<$ $0.001)$, vaginal penetration by penis $(p=0.004)$, vaginal penetration by finger ( $p=0.039$ ), penal-anal penetration $(p<0.001)$, patient position $(p=0.048)$, and sexual inexperience $(p<0.001)$. Of the 1639 patients who did not have intercourse 5 days prior, 513 (67.9\%) of the 755 sexually inexperienced and 489 (56.4\%) of the 867 sexually experienced displayed AGIs $(p<0.001)$.

Of the 1961 examinations, 1752 (89.3\%) examina-

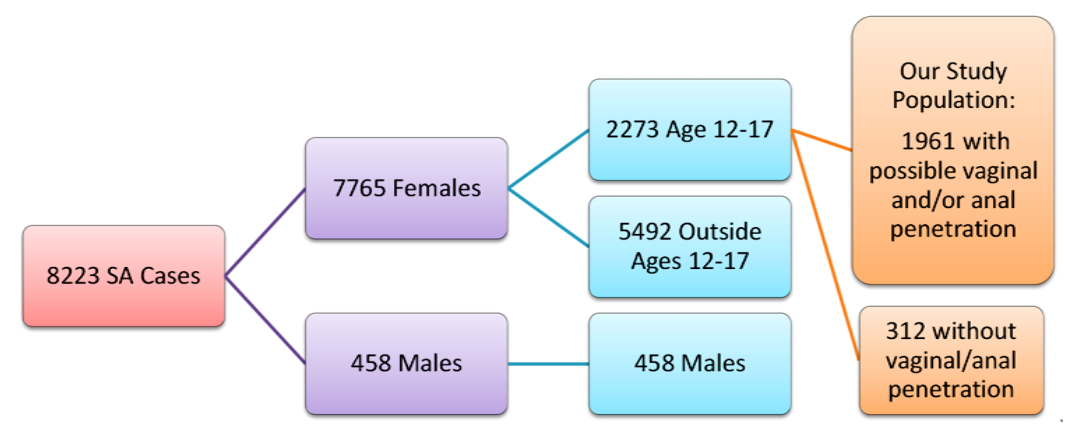

Figure 1. Flow chart of sexual assault (SA) cases during the study period (11/01/2002 to 05/31/2011). 
Table 1. Variables with statistics, comparing anogenital injury (AGI) and selected independent variable $(\mathbf{n}=1961)$.

\begin{tabular}{|c|c|c|c|c|c|}
\hline Variable & Frequency $(\%)^{\mathrm{a}}$ & Frequency with AGI (\%) ${ }^{\mathrm{b}}$ & $p$-value ${ }^{c}$ & Odds ratio $^{\mathrm{d}}$ & $95 \%$ confidence interval $^{\mathrm{d}}$ \\
\hline \multicolumn{6}{|c|}{ Anogenital injury $(n=1961)$} \\
\hline Yes & 1169 (59.6) & & & & \\
\hline No & $792(40.4)$ & & & & \\
\hline Patient age $(\mathrm{n}$ & 961) & & 0.251 & & \\
\hline 12 & $106(5.4)$ & $58(54.7)$ & & Referent & \\
\hline 13 & 233 (11.9) & $143(61.4)$ & 0.248 & 1.31 & 0.83 to 2.09 \\
\hline 14 & $374(19.1)$ & $222(59.4)$ & 0.393 & 1.21 & 0.78 to 1.87 \\
\hline 15 & $457(23.3)$ & $279(61.1)$ & 0.231 & 1.30 & 0.85 to 1.99 \\
\hline 16 & 447 (22.8) & $249(55.7)$ & 0.854 & 1.04 & 0.68 to 1.59 \\
\hline 17 & $344(17.5)$ & $218(63.4)$ & 0.111 & 1.43 & 0.92 to 2.23 \\
\hline \multicolumn{3}{|c|}{ Alcohol use by patient $(\mathrm{n}=1930)$} & $0.047^{*}$ & & \\
\hline No & $1209(62.6)$ & $699(57.8)$ & & Referent & \\
\hline Yes & $721(37.4)$ & $450(62.4)$ & $0.047^{*}$ & 1.21 & 1.00 to 1.46 \\
\hline Unknown & 31 & $20(64.5)$ & & & \\
\hline \multicolumn{3}{|c|}{ Condom use $(\mathrm{n}=1395)$} & 0.688 & & \\
\hline No & $1026(73.5)$ & $605(59.0)$ & & Referent & \\
\hline Yes & 369 (26.5) & $222(60.2)$ & 0.688 & 1.05 & 0.82 to 1.34 \\
\hline Unknown & 566 & $342(60.4)$ & & & \\
\hline \multicolumn{3}{|c|}{ Consent $(\mathrm{n}=1959)$} & 0.465 & & \\
\hline No & 1549 (79.1) & $930(60.0)$ & & Referent & \\
\hline Yes & 410 (20.9) & $238(58.0)$ & 0.465 & 0.92 & 0.74 to 1.15 \\
\hline Unknown & 2 & $1(50.0)$ & & & \\
\hline \multicolumn{3}{|c|}{ Delivery number (n = 1959) } & 0.266 & & \\
\hline 0 & 1938 (98.9) & $1152(59.4)$ & & Referent & \\
\hline$\geq 1$ & $21(1.1)$ & 15 (71.4) & 0.271 & 1.71 & 0.66 to 4.42 \\
\hline Unknown & 2 & $0(0.0)$ & & & \\
\hline \multicolumn{3}{|c|}{ Disability: cognitive $(\mathrm{n}=1961)$} & 0.947 & & \\
\hline No & 1944 (99.1) & 1159 (59.6) & & Referent & \\
\hline Yes & $17(0.9)$ & $10(58.8)$ & 0.947 & 0.97 & 0.37 to 2.55 \\
\hline Unknown & 0 & $0(0.0)$ & & & \\
\hline \multicolumn{3}{|c|}{ Disability: physical ( $\mathrm{n}=1955$ ) } & 0.785 & & \\
\hline No & 1939 (99.2) & $1156(59.6)$ & & Referent & \\
\hline Yes & $16(0.8)$ & $9(56.3)$ & 0.785 & 0.87 & 0.32 to 2.35 \\
\hline Unknown & 6 & $4(66.7)$ & & & \\
\hline
\end{tabular}




\section{Continued}

Drug use by patient $(n=1811)$

0.753

$\begin{array}{ccc}\text { No } & 1442(79.6) & 861(59.7) \\ \text { Yes } & 369(20.4) & 217(58.8) \\ \text { Unknown } & 150 & 91(60.7)\end{array}$

Referent

$0.753 \quad 0.96$

0.76 to 1.22

Patient education $(n=1940)$

College
Elementary
High School
Junior High
Unknown

$7(0.4)$
$69(3.6)$
$1432(73.8)$
$432(22.3)$
21

6 (85.7)

41 (59.4)

4.01

0.48 to 33.4

0.199

0.98

0.60 to 1.60

858 (59.9)

$255(59.0)$

Referent

0.741

0.96

0.77 to 1.20

Gravidity $(n=1960)$

$9(42.9)$

0.638

$\begin{array}{cc}0 & 1891(96.5) \\ \geq 1 & 69(3.5) \\ \text { Unknown } & 1\end{array}$

1125 (59.5)

43 (62.3)

0.639

Referent

1.13

0.69 to 1.85

Intercourse 5 days prior (1958)

$$
\text { No }
$$

Yes

Unknown

Lapse of consciousness $(n=1959)$

$\begin{array}{lc}\text { No } & 1456(74.3) \\ \text { Yes } & 503(25.7) \\ \text { nknown } & 2\end{array}$

Lubricant use ( $\mathrm{n}=1433)$

$\begin{array}{cc}\text { No } & 1373(95.8) \\ \text { Yes } & 60(4.2) \\ \text { Unknown } & 528\end{array}$

Patient marital status $(\mathrm{n}=1957)$

Cohabitating
Married
Separated
Single

Unknown

1639 (83.7)

$319(16.3)$

3

$3(0.2)$
$2(0.1)$
$52(2.7)$
$1900(97.1)$

4
$0(0.0)$

Patient marital status (collapsed) $(\mathrm{n}=1961)$

Other/Not Single

$57(2.9)$
$1900(97.1)$

1011 (61.7)

156 (48.9)

2 (66.7)

$858(58.9)$

$310(61.6)$

$1(50.0)$

$817(59.5)$

$33(55.0)$

$319(60.4)$

$<0.001^{*}$

$<0.001^{*}$

0.287

0.287

Referent

1.12

0.91 to 1.38

0.487

0.487

Referent

0.83

0.49 to 1.40

0.197

3 (100.0)

2 (100.0)

27 (51.9)

1135 (59.7)

2 (50.0)

32 (56.1)

0.586

0.586

0.86

0.51 to 1.47

1135 (59.7)
Referent 


\section{Continued}

\begin{tabular}{|c|c|c|c|c|c|}
\hline \multicolumn{3}{|l|}{ Parity $(n=1960)$} & \multicolumn{3}{|l|}{0.696} \\
\hline 0 & $1925(98.2)$ & $1147(59.6)$ & & Referent & \\
\hline$\geq 1$ & $35(1.8)$ & $22(62.9)$ & 0.696 & 1.15 & 0.57 to 2.29 \\
\hline Unknown & 1 & $0(0.0)$ & & & \\
\hline \multicolumn{6}{|c|}{ Vaginal penetration by penis $(\mathrm{n}=1961)$} \\
\hline No & $148(7.5)$ & $69(46.6)$ & & & \\
\hline Yes/Attempted & 1449 (73.9) & $878(60.6)$ & & & \\
\hline Unknown & $364(18.6)$ & $222(61.0)$ & & & \\
\hline \multicolumn{6}{|c|}{ Vaginal penetration by finger $(n=1961)$} \\
\hline No & $724(36.9)$ & $406(56.1)$ & & & \\
\hline Yes/Attempted & $786(40.1)$ & $491(62.5)$ & & & \\
\hline Unknown & $451(23.0)$ & $272(60.3)$ & & & \\
\hline \multicolumn{6}{|c|}{ Vaginal penetration by object $(n=1961)$} \\
\hline No & $1480(75.5)$ & $873(59.0)$ & & & \\
\hline Yes/Attempted & $16(0.8)$ & $10(62.5)$ & & & \\
\hline Unknown & 465 (23.7) & $286(61.5)$ & & & \\
\hline \multicolumn{6}{|c|}{ Penal-anal penetration $(n=1961)$} \\
\hline No & $1261(64.3)$ & 703 (55.7) & & & \\
\hline Yes/Attempted & $266(13.6)$ & $195(73.3)$ & & & \\
\hline Unknown & $434(22.1)$ & $271(62.4)$ & & & \\
\hline \multicolumn{6}{|c|}{ Anal penetration by finger $(n=1961)$} \\
\hline No & $1420(72.4)$ & $831(58.5)$ & & & \\
\hline Yes/Attempted & $89(4.5)$ & $54(60.7)$ & & & \\
\hline Unknown & $452(23.0)$ & $284(62.8)$ & & & \\
\hline \multicolumn{6}{|c|}{ Anal penetration by object $(n=1961)$} \\
\hline No & $1513(77.2)$ & 891 (58.9) & & & \\
\hline Yes/Attempted & $6(0.3)$ & $3(50.0)$ & & & \\
\hline Unknown & $442(22.5)$ & $275(62.2)$ & & & \\
\hline \multicolumn{3}{|c|}{ Perpetrator relationship $(\mathrm{n}=1909)$} & 0.050 & & \\
\hline Acquaintance & 1265 (66.3) & $772(61.0)$ & 0.792 & 0.97 & 0.76 to 1.23 \\
\hline Stranger & $356(18.6)$ & $220(61.8)$ & & Referent & \\
\hline Ex-Boyfriend & $61(3.2)$ & $34(55.7)$ & 0.371 & 0.78 & 0.45 to 1.35 \\
\hline Family Member & $148(7.8)$ & $71(48.0)$ & $0.004^{*}$ & 0.57 & 0.39 to 0.84 \\
\hline In-Home Resident & $28(1.5)$ & $15(53.6)$ & 0.392 & 0.71 & 0.33 to 1.54 \\
\hline Boyfriend & $51(2.7)$ & $29(56.9)$ & 0.499 & 0.81 & 0.45 to 1.48 \\
\hline Unknown & 52 & $28(53.8)$ & & & \\
\hline \multicolumn{3}{|c|}{ Perpetrator relationship (collapsed) $(n=1909)$} & 0.387 & & \\
\hline Stranger & $356(18.6)$ & $220(61.8)$ & 0.387 & 1.11 & 0.87 to 1.41 \\
\hline Not Stranger & $1553(81.4)$ & $921(59.3)$ & & Referent & \\
\hline Unknown & 52 & $28(53.8)$ & & & \\
\hline
\end{tabular}




\section{Continued}

Post-coital interval (hours) $(\mathrm{n}=1961)$

$\begin{array}{cc}0-24 & 1333(68.0) \\ 25-48 & 337(17.2) \\ 49-72 & 175(8.9) \\ 73-96 & 73(3.7) \\ 97-120 & 43(2.2)\end{array}$

Patient race $(\mathrm{n}=1961)$

\section{Asian}

48 (2.4)

African American/Black

$328(16.7)$

Filipino

$15(0.8)$

Hispanic

1048 (53.4)

Other

$32(1.6)$

White

$486(24.8)$

Native American

$4(0.2)$

Patient race (collapsed) $(n=1961)$

Non-Black

1633 (83.3)

Black

$328(16.7)$

Patient position $(n=1619)$

$\begin{array}{cc}\text { Back } & 1106(68.3) \\ \text { Multiple } & 229(14.1) \\ \text { Sitting } & 79(4.9) \\ \text { Standing } & 97(6.0) \\ \text { Stomach } & 46(2.8) \\ \text { Hands/Knees } & 20(1.2) \\ \text { Other } & 42(2.6) \\ \text { Unknown } & 342\end{array}$

Sexually inexperienced patient $(n=1942)$

$\begin{array}{cc}\text { No } & 1186(61.1) \\ \text { Yes } & 756(38.9) \\ \text { Unknown } & 19\end{array}$

Weapon involvement $(n=1868)$

$\begin{array}{lc}\text { No } & 1709(91.5) \\ \text { Yes } & 159(8.5)\end{array}$

Unknown
$<0.001^{*}$

$836(62.7)$

198 (58.8)

0.181

$0.002^{*}$

$0.003^{*}$

$<0.001^{*}$

0.158

0.236

1.47

0.78 to 2.79

189 (57.6)

8 (53.3)

0.743

Referent

637 (60.8)

12 (37.5)

288 (59.3)

3 (75.0)

0.308

0.84

0.30 to 2.37

1.14

0.89 to 1.47

$0.032^{*}$

0.44

0.21 to 0.93

0.642

1.07

0.81 to 1.42

0.495

0.23 to 21.4

0.421

$980(60.0)$

Referent

189 (57.6)

0.421

0.91

0.71 to 1.15

$0.048^{*}$

650 (58.8)

Referent

153 (66.8)

$0.024^{*}$

0.158

1.41

1.05 to 1.91

40 (50.6)

0.430

0.72

0.46 to 1.14

61 (62.9)

1.19

0.77 to 1.83

30 (65.2)

0.385

1.32

0.71 to 2.44

11 (55.0)

0.735

0.86

0.35 to 2.09

19 (45.2)

0.084

0.58

0.31 to 1.08

205 (59.9)

$<0.001^{*}$

645 (54.4)

Referent

513 (67.9)

$<0.001^{*}$

1.77

1.46 to 2.14

11 (57.9)

0.847

1013 (59.3)

93 (58.5)

0.847

Referent

0.97

0.70 to 1.35

Notes: Except for the vaginal and anal penetration variables, sample size (n) for each variable excludes the quantity of unknowns, and unknowns were not used in the statistical analysis but were included in the table for completeness. Valid statistical calculations for the penetration variables were limited to percent fre-

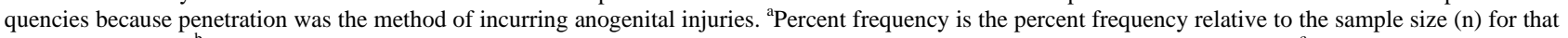
particular variable. ${ }^{b}$ Percent frequency with anogenital injury is the percent frequency relative to the total frequency of the category. ${ }^{\mathrm{c}}$ The $p$-values listed on the same row as the variable name were calculated using Pearson's chi-square test or Fisher's exact test. The p-values for each category of the variable were calculated using logistic regression. ${ }^{\mathrm{d}}$ Odds ratios and confidence intervals were calculated using logistic regression. The logistic regression was not stable for the uncollapsed marital status variable. ${ }^{*} p<0.05$. 
tions were used in the logistic regression model (Table 2). Hosmer-Lemeshow goodness-of-fit test supported the null hypothesis $(p=0.815)$ that the model fit. Statistically significant independent variables associated with AGIs in this model included age; intercourse 5 days prior; postcoital interval for 49 - 72, 73 - 96, and 97 - 120 hours; and prior sexual experience.

\section{Discussion}

We found AGIs in 59.6\% of our female minors examined as part of a forensic sexual assault procedure. This frequency is higher than the means of $45 \%$ for 10 to 14 years and $55 \%$ for 15 to 19 years found in the metaanalysis of Carter-Snell but lower than the $65.7 \%$ in the analysis by Baker et al. [5,6]. The difference may result from our narrower definition of injury that excluded erythema and swelling.

Healing of the injury over time impacts the probability of finding genital wounds during forensic examination. We expected to and did find fewer AGIs with increasing post-coital interval (decreasing AGIs from 63\% to 33\% over 5 days). This expectation was motivated by general knowledge about the healing of mucosal tissue and by the studies of Adams et al. and McCann et al. [1,7]. In the adolescent population (14 to 19 years old) of Adams et al., patients presented with progressively less AGI as time to examination increased over a span of 72 hours [7]. Depending on the severity, location, and type of injury, McCann et al. documented the disappearance of injuries as early as two days after the initial examinations in their pubertal patients (17 years old and younger) [1].

We had postulated that, similar to an adult population, sexual experience in an adolescent population would correlate with less injury. Such patients may have acquired physical changes that decrease the likelihood of detecting injury after intercourse. This postulation was congruent with our finding that sexually inexperienced patients had $11.5 \%$ more injuries compared to sexually experienced patients who did not have intercourse in the preceding 5 days.

As expected, we found sexual inexperience associated with $13.5 \%$ (OR $1.77,95 \% \mathrm{CI}=1.46$ to 2.14 ) more injury. Our findings were similar to those of the British adolescents in the study of White and Mclean who found genital injuries in $62 \%$ of sexually inexperienced patients and $46 \%$ of experienced patients [8]. The overall lower rate of AGIs in the population of White and McLean may be a result of differences in examination procedures. White and McLean performed examinations after a longer post-coital interval (90 hours for sexually inexperienced patients and 44 hours for experienced patients (two-sided $p=0.037)$ ) and may not have used advanced detection techniques. Additionally, White and McLean
Table 2. Logistic regression model with anogenital injury (AGI) as the dependent variable $(n=1752)$.

\begin{tabular}{|c|c|c|c|}
\hline Variable & Odds ratio & $p$-value & 95\% confidence interval \\
\hline \multicolumn{4}{|l|}{ Patient age } \\
\hline 12 & Referent & & \\
\hline $13-17$ & 1.08 & $0.038^{*}$ & 1.00 to 1.16 \\
\hline \multicolumn{4}{|l|}{ Alcohol use } \\
\hline No & Referent & & \\
\hline Yes & 1.24 & 0.093 & 0.96 to 1.59 \\
\hline \multicolumn{4}{|l|}{ Consent } \\
\hline No & Referent & & \\
\hline Yes & 1.14 & 0.308 & 0.89 to 1.47 \\
\hline \multicolumn{4}{|l|}{ Gravidity } \\
\hline 0 & Referent & & \\
\hline$\geq 1$ & 1.55 & 0.109 & 0.91 to 2.65 \\
\hline \multicolumn{4}{|l|}{ Drug use } \\
\hline No & Referent & & \\
\hline Yes & 1.11 & 0.450 & 0.85 to 1.45 \\
\hline \multicolumn{4}{|c|}{ Intercourse 5 days prior } \\
\hline No & Referent & & \\
\hline Yes & 0.71 & $0.022^{*}$ & 0.54 to 0.94 \\
\hline \multicolumn{4}{|c|}{ Lapse of consciousness } \\
\hline No & Referent & & \\
\hline Yes & 1.03 & 0.927 & 0.77 to 1.37 \\
\hline \multicolumn{4}{|c|}{ Post-coital interval (hours) } \\
\hline $0-24$ & Referent & & \\
\hline $25-48$ & 0.81 & 0.116 & 0.62 to 1.05 \\
\hline $49-72$ & 0.51 & $<0.001^{*}$ & 0.36 to 0.71 \\
\hline $73-96$ & 0.41 & $0.001^{*}$ & 0.25 to 0.68 \\
\hline $97-120$ & 0.25 & $<0.001^{*}$ & 0.13 to 0.50 \\
\hline \multicolumn{4}{|c|}{ Perpetrator relationship } \\
\hline Stranger & 1.01 & 0.905 & 0.78 to 1.32 \\
\hline Not stranger & Referent & & \\
\hline \multicolumn{4}{|l|}{ Patient race } \\
\hline Non-Black & Referent & & \\
\hline Black & 0.89 & 0.393 & 0.68 to 1.16 \\
\hline \multicolumn{4}{|c|}{ Sexually inexperienced patient } \\
\hline No & Referent & & \\
\hline Yes & 2.03 & $<0.001^{*}$ & 1.60 to 2.58 \\
\hline
\end{tabular}


excluded anal injuries, but our study combined anal injuries and genital injuries into a single variable (AGI).

Conversely, patients who reported intercourse within 5 days prior to the sexual assault displayed less injury $(12.8 \%$, OR $0.59,95 \% \mathrm{CI}=0.47$ to 0.76$)$ than those who did not report such activity. Our finding agrees with the study of Jones et al., in which adults, who are typically more sexually experienced, had fewer injuries than adolescents [9]. However, injuries in adolescents may also be attributable to incompletely estrogenized genital tissues.

Contrasting the findings of Sachs et al. in an estrogenized female population and Drocton et al. in an adult population, our data showed increase injury in patients reporting penetrating assault in multiple positions versus the back only position (OR $1.41,95 \% \mathrm{CI}=1.05$ to 1.91 ) $[3,4]$. McLean et al. did not find an association for position in their adult population [10]. We suspect that sexual assault in multiple positions correlates with more violent, frequent, and/or multiple episodes of rape during the single sexual assault experience. Further studies are necessary to elucidate this association.

We explored a number of variables associated with the potential ability of a patient to resist sexual activity. Patient use of alcohol was marginally associated with injury (OR 1.21, 95\% CI $=1.00$ to 1.46). The absolute percent increase was under $5 \%$, a relatively small difference. The studies of Hilden et al., Read et al., and Maguire et al. in their respective populations of adolescents and adults found no association between alcohol and genital injuries [11-13]. Given the small association found in our study and the findings by these other authors, AGIs are unlikely to have a significant association with the patient's alcohol use.

Our data include a subset of patient examined after consensual intercourse in cases of suspected statutory rape. Per California Penal Code section 261, the state of California defines "unlawful sexual intercourse" (i.e., statutory rape) as sexual intercourse with a non-spousal person under the age of 18 years (i.e., a minor). We hypothesized that the implicit physical consent in these cases would be associated with decreased genital injury findings, but our consensual and nonconsensual populations displayed similar injury frequency, $58.0 \%$ and $60.0 \%$ ( $p>0.05)$, respectively. Jones et al. found frequencies of $73 \%$ for consensual and $85 \%$ for nonconsensual assault $(p>0.05)$ but used a broader definition of injury [14].

Our findings of equally high AGI prevalence during consensual intercourse may be due to the inclusion bias of a more injured population in our patient population. The vast majority of consensual statutory rape cases are not reported, as deduced by the large discrepancy between the number of estimated total and reported consensual intercourse $[15,16]$. Patients may present to med- ical primary care or an emergency department provider for pain or bleeding following consensual intercourse either through their own decisions or because of the influence of parents, authority figures, or friends. This initial medical contact may lead to a sexual assault examination and increase the decision to report. For example a parent, counselor, or friend may discover information about the sexually active minor when the patient manifests signs and symptoms post-act, such as atalgic gait from perineal pain due to injury, or blood on undergarments or sheets. These patients may be more likely to present for examination due to the third person's discovery, thus biasing the sample to include the injured statutory rape patients over all those engaging in consensual intercourse with an adult.

We found no association between lapse of consciousness and AGIs (approximately 60\% with or without lapse of consciousness). One might hypothesis that perpetrators would need to use more force to complete a sexual assault in a conscious patients and use less force with patients subdued by drugs or alcohol. According to this hypothesis, we would expect to find decreased AGIs in patients who reported a lapse of consciousness. However, we failed to find a significant difference. Again, this may be due to selection bias as patients who suffer a lapse of consciousness and discover genital pain or injury upon return to consciousness may be more likely to report the potential assault and have an examination. In contrast, patients without any pain or symptoms may not suspect that they were assaulted during the lapse of consciousness.

Our data showed no association between AGIs and patient drug use, cognitive disabilities, physical disabilities, gravidity, or parity, nor for perpetrator use of lubricant, condoms, or weapons. Similarly the relationship of the patient and perpetrator lacked association with injury. We found no association for age, education, marital status, and race.

\section{Conclusion}

In conclusion, our bivariate analysis found increasing post-coital interval and sexual experience to correlate with less injury. Our model showed a significant association between AGIs in sexually assaulted adolescents and only a few variables: intercourse 5 days prior, post-coital interval, and sexual inexperience.

\section{Limitations}

Our data set lacked complete data for 728 examinations. We combined genital injury and anal injury into the single variable of anogenital injury in order to facilitate computations. However, this prevents distinction of associations for genital injury and anal injury independent- 
ly, particularly when penetration occurred only in the vagina or rectum. We relied on patient self-report regarding consent which may suffer from recall and misclassification bias. Our study population was limited to a single metropolitan area and our findings may not be generalizable to other demographic populations.

\section{REFERENCES}

[1] J. McCann, S. Miyamoto, C. Boyle and K. Rogers, "Healing of Nonhymenal Genital Injuries in Prepubertal and Preadolescent Girls: A Descriptive Study,” Pediatrics, Vol. 120, No. 3, 2007, pp. 1000-1011. http://dx.doi.org/10.1542/peds.2006-0230

[2] J. M. Watkeys, L. D. Price, P. M. Upton and A. Maddocks, "The Timing of Medical Examination Following an Allegation of Sexual Abuse: Is This an Emergency?” Archives of Disease in Childhood, Vol. 93, No. 10, 2008, pp. 851-856. http://dx.doi.org/10.1136/adc.2007.123604

[3] C. J. Sachs and L. D. Chu, "Predictors of Genitorectal Injury in Female Victims of Suspected Sexual Assault," Academic Emergency Medicine, Vol. 9, No. 2, 2002, pp. 146-151. http://dx.doi.org/10.1111/j.1553-2712.2002.tb00232.x

[4] P. Drocton, C. Sachs, L. Chu and M. Wheeler, "Validation Set Correlates of Anogenital Injury after Sexual Assault," Academic Emergency Medicine, Vol. 15, No. 3, 2008, pp. 231-238. http://dx.doi.org/10.1111/j.1553-2712.2008.00050.x

[5] C. J. Carter-Snell, “Understanding Women's Risks for Injury from Sexual Assault,” Ph.D. Thesis, University of Alberta, Edmonton, 2007.

[6] R. B. Baker and M. S. Sommers, "Relationship of Genital Injuries and Age in Adolescent and Young Adult Rape Survivors," Journal of Obstetric, Gynecologic, and Neonatal Nursing, Vol. 37, No. 3, 2008, pp. 282-289. http://dx.doi.org/10.1111/j.1552-6909.2008.00239.x

[7] J. A. Adams, B. Girardin and D. Faugno, “Adolescent Sexual Assault: Documentation of Acute Injuries Using Photo-Colposcopy," Journal of Pediatric and Adolescent Gynecology, Vol. 14, No. 4, 2001, pp. 175-180. http://dx.doi.org/10.1016/S1083-3188(01)00126-7
[8] C. White and I. McLean, “Adolescent Complainants of Sexual Assault; Injury Patterns in Virgin and Non-Virgin Groups,” Journal of Clinical Forensic Medicine, Vol. 13, No. 4, 2006, pp. 172-180. http://dx.doi.org/10.1016/j.jcfm.2006.02.006

[9] J. S. Jones, L. Rossman, B. N. Wynn, C. Dunnuck and N. Schwartz, "Comparative Analysis of Adult versus Adolescent Sexual Assault: Epidemiology and Patterns of Anogenital Injury,” Academic Emergency Medicine, Vol. 10, No. 8, 2003, pp. 872-877. http://dx.doi.org/10.1111/j.1553-2712.2003.tb00631.x

[10] I. McLean, S. A. Roberts, C. White and S. Paul, "Female Genital Injuries Resulting from Consensual and NonConsensual Vaginal Intercourse,” Forensic Science International, Vol. 204, No. 1-3, 2011, pp. 27-33. http://dx.doi.org/10.1016/j.forsciint.2010.04.049

[11] M. Hilden, B. Schei and K. Sidenius, "Genitoanal Injury in Adult Female Victims of Sexual Assault," Forensic Science International, Vol. 154, No. 2-3, 2005, pp. 200205. http://dx.doi.org/10.1016/j.forsciint.2004.10.010

[12] K. M. Read, J. A., Kufera, M. C. Jackson and P. C. Dischinger, "Population-Based Study of Police-Reported Sexual Assault in Baltimore, Maryland,” The American Journal of Emergency Medicine, Vol. 23, No. 3, 2005, pp. 273278. http://dx.doi.org/10.1016/j.ajem.2005.01.002

[13] W. Maguire, E. Goodall and T. Moore, "Injury in Adult Female Sexual Assault Complainants and Related Factors,” European Journal of Obstetrics, Gynecology, and Reproductive Biology, Vol. 142, No. 2, 2009, pp. 149-153. http://dx.doi.org/10.1016/j.ejogrb.2008.10.005

[14] J. S. Jones, L. Rossman, M. Harman and C. C. Alexander, "Anogenital Injuries in Adolescents after Consensual Sexual Intercourse,” Academic Emergency Medicine, Vol. 10, No. 12, 2003, pp. 1378-1383. http://dx.doi.org/10.1111/j.1553-2712.2003.tb00013.x

[15] J. C. Abma, G. M. Martinez, W. D. Mosher and B. S. Dawson, "Teenagers in the United States: Sexual Activity, Contraceptive Use, and Childbearing, 2002,” Vital and Health Statistics, Vol. 23, No. 24, 2004.

[16] K. Troup-Leasure and H. N. Snyder, "Statutory Rape Known to Law Enforcement (NCJ 208803)," Juvenile Justice Bulletin, 2005. 